\title{
Idosos Soropositivos: A Construção de Significados para o Envelhecimento com HIV/Aids
}

\author{
Isadora Cristina Putti Paludo ${ }^{1}$ \\ ${ }^{1}$ Universidade Federal de Santa Catarina, \\ SC, Brasil.
}

\author{
Luisa da Rosa Olesiak ${ }^{2}$ \\ ${ }^{2}$ Universidade Federal de Santa Maria, \\ RS, Brasil.
}

\author{
Alberto Manuel Quintana² \\ ${ }^{2}$ Universidade Federal de Santa Maria, \\ RS, Brasil.
}

\begin{abstract}
Resumo: O processo de envelhecimento traz o enlace da representação simbólica da velhice e suas implicações inconscientes. Os idosos soropositivos lidam com a Aids, doença cujas representações ressoamno narcisismo dosujeito. Frenteaisso, este estudo objetivou compreendercomo seconstrói a experiência de envelhecer com o diagnóstico de HIV/Aids. O estudo é qualitativo e descritivo, com referencial teórico psicanalítico. Participaram sete idosos, três mulheres e quatro homens, diagnosticados com HIV/Aids no período de 2016 e 2017 e que realizavam acompanhamento da doença em um hospital público no interior do Rio Grande do Sul. Os instrumentos de coleta de dados utilizados foram questionário sociodemográfico e entrevista semiestruturada. A partir da análise de conteúdo de Bardin (2010) foram construídas três categorias: a) "Eu tenho cara de velho? Eu ajo como velho?!”; b) “- Tu tá com Aids! . . - Eu perdi o chão”; e c) "Isso aqui não vai sair das quatros paredes, eu não vou abrir para ninguém”. Constatou-se nos relatos dos participantes que tinham dificuldade de apreciar sua imagem frente ao espelho, pois corriam o risco de se defrontar com as marcas do envelhecer e do adoecer. Ademais, o diagnóstico positivo para HIV gerava um processo de luto e evidenciava horror, por isso mantinha-se em sigilo. Nesse sentido, torna-se fundamental oferecer um cuidado mais sensível e integral para a saúde dos idosos que são soropositivos, pois esse diagnóstico abala, além da vida afetivo-sexual, o processo singular de envelhecimento, por colocar em prova questões estruturantes da identidade.
\end{abstract}

Palavras-chave: Envelhecimento, HIV, Síndrome de Imunodeficiência Adquirida, Psicanálise.

\section{Seropositive Older Adults: The Construction of Meanings for Aging with HIV/AIDS}

\begin{abstract}
Aging promotes a series of symbolic representation of old age and its unconscious implications. This process is yet more complex for HIV-positive older adults, who deal with a disease that impacts the subject's narcissism. Thus, from a psychoanalytic perspective, this qualitative descriptive study aimed to understand how seropositive individuals construct the experience of aging. The sample consisted of seven older adults (three women and four men) diagnosed with HIV/AIDS between 2016 and 2017, and who were monitoring the disease in a public hospital in the countryside of Rio Grande do Sul. Data were collected by means of a sociodemographic questionnaire and a semi-structured interview and analyzed in the light of Bardin's (2009) content analysis, resulting in three categories: 1) “'Am I old? Do I act like I'm old?!”“; 2) ““--You have AIDS! (... - I feel lost;”“ and 3) “This stays between us, I won't tell anyone”. Participants' reported difficulty in looking at themselves in the mirror, for they could see the marks
\end{abstract}


of both aging and the disease. HIV diagnosis caused them grief and horror, so that it remained confidential. The results highlight the relevance in offering a more sensitive and integral care for HIV-positive older adults, since this diagnosis undermines not only their emotional-sexual life, but also the singular process of aging, putting in test structuring questions of the identity.

Keywords: Aging, HIV, Acquired Immunodeficiency Syndrome, Psychoanalysis.

\title{
Ancianos Seropositivos: Construcción de Significados para el Envejecimiento con VIH/sida
}

\begin{abstract}
Resumen: El proceso de envejecimiento trae el vínculo de la representación simbólica de la vejez y sus implicaciones inconscientes. Los ancianos seropositivos tratan con el sida, enfermedad que tiene representaciones resonantes en el narcisismo del sujeto. Frente a eso, este estudio se propuso comprender cómo se construye la experiencia de envejecer con el diagnóstico de VIH/sida. Este es un estudio cualitativo y descriptivo, con marco teórico psicoanalítico. Participaron siete ancianos (tres mujeres y cuatro hombres) diagnosticados con VIH/sida en el período de 2016 y 2017 y que realizaban monitoreo de la enfermedad en un hospital público del estado de Rio Grande do Sul (Brasil). Los instrumentos utilizados en la recopilación de datos fueron cuestionario sociodemográfico y entrevista semiestructurada. Con base en el análisis de contenido de Bardin se construyeron tres categorías: “¿Parezco viejo? ¿izActúo como viejo?! 2) “¡Usted tiene sida! (...) - Se me cayó el mundo encima” y 3) "Esto no va a salir de aquí, no lo voy a decir a nadie”. Se constató en los relatos de los participantes una dificultad para apreciar su imagen frente al espejo, debido al riesgo de enfrentarse con las marcas del envejecimiento y de la enfermedad. El diagnóstico positivo para elVIH generaba un proceso de duelo y evidenciaba el horror en los participantes, por lo que lo mantenían en secreto. En este sentido, es fundamental ofrecer un cuidado más sensible e integral para la salud de los ancianos seropositivos, puesto que ese diagnóstico afecta mucho, además de la vida afectiva y sexual, el proceso singular de envejecimiento y pone a prueba cuestiones estructurantes de identidad.
\end{abstract}

Palabras clave: Envejecimiento, VIH, Síndrome de Inmunodeficiencia Adquirida, Psicoanálisis.

\section{Introdução}

Falar do envelhecimento parece causar estranheza na maioria das pessoas, pois situa-se no campo do interdito, daquelas coisas sobre as quais é melhor não falar e que causam mal-estar (Rosa \& Vilhena, 2016). Contudo, esse é um processo irreversível, que se inscreve no tempo, começa com o nascimento e progride inexoravelmente até a finitude do indivíduo (Messy, 1992). Segundo Elias (2001), ser velho é uma construção que parte da interiorização de uma identidade individual e coletiva e, portanto, não é algo que ocorre de forma homogênea.

O conceito deidoso estabelecido pela Organização das Nações Unidas por meio da Resolução 39/125, considera como idosas as pessoas com sessenta anos ou mais que vivem em países em desenvolvimento. Já para os países desenvolvidos, idosos são aqueles que têm 65 anos ou mais (Organização das Nações Unidas, 2003). Sendo assim, o critério cronológico é um dos mais utilizados para definir o ser idoso. Segundo Neri (1991), as idades passam a funcionar como relógios sociais, estabelecendo agendas para o tempo e o ritmo esperado do desenvolvimento humano.

Nesse sentido, o trabalho psíquico que acontece no envelhecimento não diz respeito só às condições sociais da velhice, visto que faz eco com experiências psíquicas complexas que estruturam a psique de forma nodal (Cherix, 2015). Logo, a maneira como cada um reage ao envelhecimento não deixa de estar relacionada com as primeiras experiências da infância, que 
serviram de base estruturante para a constituição dos alicerces da subjetividade (Rosa \& Vilhena, 2015).

Sabe-se que as pessoas estão envelhecendo em ritmo ascendente de crescimento e essa constatação demonstra que é necessário voltar o olhar para questões referentes ao envelhecer, pois é um fenômeno que traz implicações de ordem biológica, cultural, social e psicológica (Altman, 2011; Cherix, 2015; Rosa \&Vilhena, 2016). Frente ao resgate da vivência dos idosos a partir da subjetividade, considera-se fundamental uma compreensão dos estigmas e transformações em torno da imagem do idoso e de sua sexualidade, especialmente quanto ao estigma da infecção pelo HIV/Aids.

Desse modo, é necessário ter a percepção de que eles são sujeitos com existências particulares e históricas, constituídos não apenas por uma doença crônica relacionada a estigmas e preconceitos, mas por uma significação que engloba o todo de suas vidas (Bacchini, Alves, Ceccarelli, \& Moreira, 2012; Pinheiro, 2013; Saldanha, Araújo, \& Sousa, 2009). Atualmente, o HIV/Aids está se tornando cada vez mais frequente entre a população idosa brasileira. Segundo os últimos Boletins Epidemiológicos do Ministério da Saúde, verifica-se uma elevação no número de casos notificados na faixa etária igual ou superior a sessenta anos (Ministério da Saúde, 2017).

A problemática do envelhecimento e a Aids no Brasil relaciona-se à questão cultural e de exclusão, sobretudo ao preconceito social relacionado à prática de sexo nessa idade (Saldanha et al., 2009; Santos \& Assis, 2011). A possibilidade de uma pessoa com mais de sessenta anos ser infectada pelo HIV parece ser mínima para a sociedade e para os próprios idosos, uma vez que a sexualidade nessa faixa etária ainda é tratada como tabu (Serra, Sardinha, Pereira, \& Lima, 2013; Silva \& Saldanha, 2012).

Conforme Veras (2007), o vírus coloca em questão não só as fantasias inconscientes da sexualidade, mas também o imaginário social sobre o corpo e sua importância na construção da subjetividade. Desse modo, com a descoberta do diagnóstico, o sujeito soropositivo pode entrar em um processo de menos-valia provocado a partir da desestruturação psíquica (Pinheiro, 2013; Silva \& Saldanha, 2012; Villela, 2013).

Por isso, é necessário desmitificar a invisibilidade sexual dos idosos, a fim de lhes garantir uma vida sexual saudável e contínua, o que lhes é de direito (Santos \& Assis, 2011). Afinal, o idoso tem tanta vontade de sentir contato físico quanto jovens e adultos, e continua expressando sua sexualidade até o fim da vida. Porém, para o social, o corpo envelhecido não teria mais interesse como objeto de investimento (Cherix, 2015).

A respeito disso, parece existir uma cegueira por parte da maioria da população quando se trata dos idosos e suas singularidades, pois cultua-se a juventude e a atividade como formas de esconder as marcas da passagem do tempo (Cherix, 2015; Rosa \& Vilhena, 2016). Assim, são propostos estereótipos de beleza que passam a ser vistos como modelos de corpo ideal e que geralmente são associados ao poder e à aceitação social (Rosa, Veras, \& Assunção, 2015).

Desse modo, entende-se que a presente pesquisa pode contribuir para o conhecimento mais aprofundado sobre como ocorre o processo de busca por significados e quais sentidos os idosos soropositivos constroem para suas vivências. Frente ao universo complexo que se estabelece no processo de envelhecimento, surge o interesse em escutar esses sujeitos e conhecer o modo como eles significam seus corpos, suas modificações corporais e suas histórias de vida antes e após o diagnóstico de HIV/Aids.

\section{Método}

\section{Delineamento e participantes}

Esta pesquisa consiste em um estudo qualitativo e descritivo com referencial teórico psicanalítico. Participaram sete idosos, três mulheres e quatro homens, com idades de 61 a 69 anos. Os critérios de inclusão foram: homens ou mulheres com faixa etária de 60 a 70 anos, diagnosticados com HIV/Aids, identificados no período de 2014 a 2017 pelo Sistema de Informações de Agravos de Notificação (Sinan) e com acompanhamento da doença em um hospital público do interior do Rio Grande do Sul. O critério de exclusão foi o participante não ter capacidade cognitiva ou apresentar dificuldades na fonação ou audição que lhe impossibilitassem de participar da entrevista.

O número de participantes foi definido com base no critério de saturação da amostra, visto que as informações se repetiam com os sete participantes. Conforme Minayo (2011), a saturação ocorre quando o pesquisador alcança a compreensão da homogeneidade, da intensidade e da diversidade das informações necessárias para a pesquisa. Além disso, segundo Fontanella, Ricas e Turato (2008), se as informações coletadas repetirem-se entre os participantes e novas entrevistas não proporcionem acréscimos 
significativos para a discussão do estudo, o pesquisador poderá fechar o grupo de pesquisa.

\section{Instrumentos}

Foi utilizado um questionário de dados sociodemográficos, visando coletar informações relevantes para a caracterização da amostra, além de um roteiro de entrevista semiestruturada. Segundo Triviños (1987), a entrevista semiestruturada é composta por questionamentos básicos apoiados em teorias e hipóteses relacionadas ao tema da pesquisa. Dessa forma, as questões norteadoras do estudo abrangeram aspectos da subjetividade envolvida no processo de envelhecer com HIV/Aids; da relação com o espelho e a construção da imagem corporal dos idosos; dos significados conferidos à sexualidade, à doença $\mathrm{e}$ às modificações corporais; e, por fim, os sentidos atribuídos a ser idoso soropositivo na sociedade atual.

\section{Procedimentos e coleta de dados}

Obteve-se autorização institucional do hospital para a realização da pesquisa e o projeto foi aprovado pelo Comitê de Ética em pesquisa com seres humanos da instituição de ensino, sob o registro no CAAE 88154718.6.0000.5346. Na presente pesquisa, foram preservados os princípios éticos da pesquisa com seres humanos presentes na Resolução nº 466/2012 do Conselho Nacional de Saúde, bem como foram respeitados os princípios éticos da Resolução no 510/2016, legislação vigente de pesquisa com seres humanos nas áreas de ciências sociais e humanas.

Primeiramente, realizou-se o levantamento de dados no banco do Sinan, por meio do Núcleo de Vigilância Epidemiológica do referido hospital. Foram identificados 38 casos notificados entre 2014 e 2017 de sujeitos na faixa etária de 60 a 70 anos. O maior número de casos acometia o sexo masculino - havia 27 homens e 11 mulheres infectados e a infecção ocorreu predominantemente por via sexual. Foi possível constatar que em 2016 e 2017 houve um aumento no número de pessoas infectadas, 27 casos, se comparados aos anos de 2014 e 2015, quando houve 11 casos.

Inicialmente, pensou-se em entrar em contato via telefone com os participantes para convidá-los a participar do estudo e, assim, agendar um encontro para a realização da entrevista. Contudo, percebeu-se que essa estratégia não estava sendo eficaz, pois os números estavam desatualizados, bem como houve grande recusa e medo da exposição entre os que receberam a ligação. Então, após essa dificuldade inicial, optou-se por trabalhar junto ao setor de infectologia do hospital. Ao repassar as informações para o respectivo setor, tomou-se conhecimento do agendamento de oito consultas. A partir disso, os participantes passaram a ser acessados pela pesquisadora no momento em que iam realizar consulta.

Os idosos convidados a integrar o estudo receberam explicações sobre os aspectos da pesquisa, bem como assinaram o Termo de Consentimento Livre e Esclarecido (TCLE). As entrevistas foram realizadas em uma sala do hospital e tiveram duração média de 40 minutos. Após o encontro, realizou-se a transcrição das falas dos participantes, que passaram a ser identificados pelos códigos MX (para mulheres) e HX (para homens). Foram realizadas um total de 7 entrevistas.

\section{Análise dos Dados}

Os dados foram analisados a partir da Análise de Conteúdo de Bardin (2010), por meio da qual se procurou sentidos e compreensões comuns aos dados coletados e se identificou categorias para serem analisadas e discutidas. Nessa técnica de análise, para que se possa extrair tendências claras e chegar a uma conclusão, é necessário realizar um estudo minucioso do conteúdo do material obtido, das palavras e frases que o compõem.

O processo de categorização implicou na leitura atenta e frequente das verbalizações, realizada por dois membros da equipe, buscando um ordenamento das mensagens a partir do suporte de conhecimentos científicos. Para a elucidação do fenômeno, foram considerados dois critérios para a categorização dos dados: a repetição, que demonstra o conteúdo emergente no discurso dos entrevistados; e o critério da relevância, segundo o qual se coloca em destaque um aspecto rico em conteúdo (Turato, 2013). Ambos analisaram separadamente as entrevistas e debateram o conteúdo mais frequente e o mais relevante, de modo que as categorias resultaram de consenso.

\section{Resultados e discussão}

A seguir será apresentada uma tabela para melhor compreensão dos dados sociodemográficos dos entrevistados. A disposição dos participantes 
na tabela foi baseada na ordem em que ocorreram as respectivas entrevistas, realizadas entre junho e setembro de 2018. Todos os participantes estavam em acompanhamento no hospital onde foi realizado o estudo e tinham consultas agendadas no setor de infectologia a cada dois ou três meses.

Tabela 1

Características sociodemográficas dos participantes.

\begin{tabular}{|c|c|c|c|c|c|c|c|}
\hline Participantes & Idade & Estado civil & Escolaridade & Profissão & Religião & Renda & Sinan \\
\hline M1 & 67 anos & Divorciada & $\begin{array}{c}\text { Ensino Médio } \\
\text { incompleto }\end{array}$ & Aposentada & Umbanda & $\begin{array}{c}\text { Até um } \\
\text { salário-mínimo }\end{array}$ & 2017 \\
\hline $\mathrm{H} 1$ & 68 anos & Viúvo & $\begin{array}{c}\text { Ensino } \\
\text { Fundamental } \\
\text { incompleto }\end{array}$ & Aposentado & Católico & $\begin{array}{l}\text { Até um } \\
\text { salário-mínimo }\end{array}$ & 2017 \\
\hline $\mathrm{H} 2$ & 69 anos & Divorciado & $\begin{array}{c}\text { Ensino } \\
\text { Fundamental } \\
\text { completo }\end{array}$ & Aposentado & $\begin{array}{c}\text { Sem } \\
\text { religião } \\
\text { definida }\end{array}$ & $\begin{array}{c}\text { Até dois } \\
\text { salários-mínimos }\end{array}$ & 2017 \\
\hline M2 & 64 anos & Casada & $\begin{array}{c}\text { Ensino } \\
\text { Fundamental } \\
\text { incompleto }\end{array}$ & $\begin{array}{l}\text { Dona de } \\
\text { casa }\end{array}$ & $\begin{array}{c}\text { Sem } \\
\text { religião } \\
\text { definida }\end{array}$ & $\begin{array}{l}\text { Até um } \\
\text { salário-mínimo }\end{array}$ & 2016 \\
\hline H3 & 66 anos & Viúvo & $\begin{array}{c}\text { Ensino } \\
\text { Fundamental } \\
\text { completo }\end{array}$ & Aposentado & Católico & $\begin{array}{l}\text { Até um } \\
\text { salário-mínimo }\end{array}$ & 2016 \\
\hline $\mathrm{H} 4$ & 62 anos & Solteiro & $\begin{array}{c}\text { Ensino } \\
\text { Fundamental } \\
\text { incompleto }\end{array}$ & Do lar & Espírita & $\begin{array}{l}\text { Até um } \\
\text { salário-mínimo }\end{array}$ & 2016 \\
\hline M3 & 61 anos & Divorciada & $\begin{array}{l}\text { Ensino médio } \\
\text { incompleto }\end{array}$ & Aposentada & Católica & $\begin{array}{l}\text { Até um } \\
\text { salário-mínimo }\end{array}$ & 2016 \\
\hline
\end{tabular}

Sinan: Sistema de Informações de Agravos de Notificação.

O estudo foi composto por sete participantes, identificados com HIV/Aids pelo Sinan nos anos de 2016 e 2017, cuja escolaridade variou de Ensino Fundamental incompleto a Ensino Médio incompleto, eram aposentados e tinham renda de até um salário-mínimo. A maior parte eram divorciados, moravam sozinhos e tinham alguma crença espiritual que auxiliava a significar os episódios de suas vidas.

A partir da apresentação dos dados prévios que caracterizam os perfis dos participantes, três categorias que retratam como idosos com HIV/Aids significam suas experiências foram construídas por meio da Análise de Conteúdo de Bardin (2010). A primeira categoria, "Eu tenho cara de velho? Eu ajo como velho?", problematizou os olhares sobre o envelhecer, os registros que passaram a marcar o corpo e a imagem, além de debater questões do narcisismo. A segunda categoria, “- Tu tá com Aids! ... - Eu perdi o chão”, abordou o processo de luto desencadeado pela descoberta do diagnóstico e os sentimentos diante da doença. Já na última categoria, "Isso aqui não vai sair das quatros paredes, eu não vou abrir pra ninguém”, refletiu-se sobre o não compartilhamento da doença e o medo do estigma e da discriminação.

\section{"Eu tenho cara de velho? Eu ajo como velho?"}

Os participantes questionavam seus hábitos e comportamentos buscando respostas que justificassem a maneira como se percebiam nessa fase da vida. Para muitos, o modo como pensavam em si mesmos permitia construir significados sobre o que é o processo de envelhecimento. No trecho a seguir, M1 reflete acerca do que seriam atividades consideradas para velhos, assim como enfatiza a importância do pensamento na percepção de si: "A gente leva a vida que a gente pensa, somos o que pensamos. .. Tem pessoas da minha idade que tão fazendo tricô, crochê, tão vendo novela, tão tomando chá da cinco... Eu gosto de bater papo, de fazer festa!' (M1). 
Outro ponto destacado nas entrevistas foi a dicotomia entre os conceitos de velho e de idoso. Para a maior parte dos participantes, há diferença no tratamento quando uma pessoa se refere a outra usando um ou outro termo. Notou-se nos discursos que o termo velho era carregado de representações de decrepitude e incapacidade, conforme as falas a seguir: "Velho é estupidez... tá dando um chega pra lá. ... Velho é agressivo, desprezivel” (H2); “A pessoa velha ninguém dá bola, entendeu, porque é velho?" (H4). Contudo, apenas H1 e H3 acreditavam que os termos tinham os mesmos significados e não traziam um sentido depreciativo aos sujeitos: "Eu fico faceiro... velho, idoso, pra mim tá bom" (H3).

Com as novas configurações do envelhecimento, pode ser considerado velho a pessoa que perdeu a capacidade ou as habilidades para exercer sua vida e ficou dependente dos cuidados dos outros, enquanto idoso é aquele que possui independência e autonomia para realizar suas atividades e manter-se ativo na sociedade (Altman, 2011). Diante disso, no mundo ocidental capitalista, ninguém quer ser velho, na medida em que ser velho é sinônimo de "incapacidade" física, intelectual e psíquica (Vilhena, Novaes, \& Rosa, 2014). Contudo, a velhice é um destino singular, em que cada um envelhece a seu próprio modo, pois cada um inscreverá algo que lhe é próprio (Corrêa, 2003; Silva \& Finocchio, 2011).

Para os participantes era importante cultuar a juventude, pois esse culto é valorizado socialmente e seria uma forma de tentar remediar o contato com a velhice, o que repercute em uma posição subjetiva de negação dessa fase da vida, como indicam $\mathrm{H1}$ e H4: "Pela idade que eu tô e com os problemas que eu tive, eu me considero novo" (H1); "Eu não me considero uma pessoa velha” (H4). Já para M1, valorizar e investir em seu corpo era uma tentativa de manter a ilusão narcísica de que seu corpo não estava envelhecendo: “Às vezes eu passo por ridícula... a minha saia tem $35 \mathrm{~cm}$, não tenho varizes, minhas pernas são bonitinhas, meu seio não écaído.... Então eu me acho jovem pra idade que eu tenho" (M1).

Se por um lado existe o reconhecimento do que é ser uma pessoa idosa, por outro, simultaneamente os participantes consideram que ainda não o são. Isso remete ao mecanismo de defesa de renegação de Freud, segundo o qual o sujeito se recusa a reconhecer uma percepção negativa, ou seja, uma falta (Roudinesco \& Plon, 1998). Assim, por meio desse mecanismo, os participantes podem continuar se considerando jovens a despeito de saberem que já não o são mais, o que demonstra que, em especial na velhice, o corpo recebe significados que remetem à juventude.

Percebe-se em M1 uma tentativa de disfarçar os indícios do processo de envelhecimento, pois ela constrói um sentido de jovialidade para seu corpo motivada pelo fato de as modificações no corpo mudarem a forma como ele é visto e nomeado pelo outro. Dessa maneira, segundo Vilhena et al. (2014), o processo de adultescência tem se configurado como uma eterna busca pela aparência jovem, seja no corpo seja nas roupas e no estilo de vida que as pessoas adotam na sociedade.

Atualmente, desenvolve-se, em ritmo crescente, as ofertas por tratamentos médicos, prescrição de dietas e cirurgias plásticas como forma de postergar a aproximação das pessoas com o envelhecimento e com a morte (Rosa et al., 2015). Nesse tocante, a dificuldade em lidar com o tempo é comum a várias idades, mas ela se evidencia de maneira diferente na pessoa idosa, já que o corpo que está diferente escancara essa relação com o tempo (Aragão \& Chariglione, 2019; Mucida, 2017). Afinal, no corpo se revela uma velhice não desejada que assusta os sujeitos como se fosse uma grande ameaça, pois não se quer ser velho ou parecer velho em uma sociedade que supervaloriza o novo e o belo.

$\mathrm{O}$ relato de $\mathrm{H} 2$ revelou a dificuldade em lidar com a passagem do tempo e demonstrou uma preferência pelas recordações de como era sua imagem no passado. Dessa forma, ele evita confrontar-se com um corpo que agora é marcado por outro registro: o envelhecer. Mucida (2017) elucida o desafio da apropriação da velhice pelo sujeito argumentando que a despeito do envelhecimento, existem aspectos que jamais envelhecem em cada um, visto a lógica da atemporalidade psíquica. Frente a isso, o sujeito assume a perspectiva de que o tempo não passou, o que pode repercutir em uma dificuldade de reconhecer sua imagem real.

Conforme Cherix (2015), é a partir da imagem corporal inconsciente que cada sujeito representa seu próprio corpo, pois tal imagem se integra à identidade, e esse processo possibilita o reconhecimento do eu em vários momentos da vida, apesar das modificações do corpo ao longo do tempo. Logo, H2 apresentava a mobilização de questões narcísicas demonstrando ter dificuldade em lidar com o descompasso entre o corpo temporal e o inconsciente atemporal. O participante relatou que nas redes sociais usava uma foto que não condizia com sua imagem atual, 
o que demonstra como o processo de envelhecimento coloca em prova questões estruturantes da identidade.

Eu quero me sentir como eu tivesse os meus 40 e poucos. . . . Foto eu tô evitando de tirar porque eu acho que quando eu era novo eu era bem melhor, mas eu já tirei muita foto... tenho um álbum de modelo [risada]. No meu Facebook eu tenho uma foto de quando eu era novo, eu não botei de agora... eu botei de quando eu tinha 30 e poucos anos $(\mathrm{H} 2)$.

Para Corrêa (2003), o sujeito constrói sua realidade a partir do encontro com sua imagem no espelho. Nesse sentido, no envelhecimento parece ocorrer uma espécie de reedição do estádio do espelho, isto é, uma reexperiência do espelho em que o sujeito se descobre modificado pelos irremediáveis sinais do tempo. Para Lacan (1966/1998), o estádio do espelho é um modelo que atravessa toda a vida do sujeito e representa a relação libidinal com sua imagem corporal, iniciada quando ainda é bebê. Desse modo, a imagem constituinte do eu ideal seria fruto da busca constante do sujeito por recuperar uma satisfação desfrutada na perfeição narcisista da infância (Baldin \&Vidal, 2017; Cherix, 2015; Rosa \& Vilhena, 2015).

Quando os participantes foram questionados sobre como se sentiam quando olhavam sua imagem no espelho, notou-se que havia diferentes significações para essa mesma experiência. Enquanto M2, $\mathrm{M} 3$, $\mathrm{H} 1$ e $\mathrm{H} 2$ reconheciam os sinais da velhice e as castrações sofridas ao longo do tempo, Ml optava por não se olhar para evitar a emergência de sentimentos negativos e a revelação das marcas de sua finitude. Os recortes a seguir ilustram essas representações dos entrevistados: "Eu não tinha o rosto envelhecido de agora. . . ., mas é a lei da vida a gente envelhecer, é a lei da gravidade" (M3); "Eu não me olho no espelho. O meu espelho sou eu mesma, a minha cabeça. . . . Tenho um espelho de dois metros no meu quarto que eu não me olho, que é só pra bonito" (M1).

Quando o sujeito não se reconhece em sua própria imagem, ele pode permanecer fixado a um tempo passado, rejeitando o presente. Adescoberta dos sinais que marcam a passagem do tempo causa um sentimento de estranheza a partir do qual surgem dúvidas e incertezas sobre si mesmo (Aragão \& Chariglione, 2018; Corrêa, 2003; Mucida, 2017). Segundo Goldfarb (1998), a dificuldade no reconhecimento da imagem no espelho marca a fase do "espelho negativo", na qual se dá o não-reconhecimento do envelhecimento do corpo, olha-se no espelho e se diz "esse não sou eu".

Ao mesmo tempo em que o participante $\mathrm{H} 2 \mathrm{admi}$ tia as marcas do tempo em seu corpo, ele se esquivava do encontro com o velho do espelho e tinha a necessidade de reforçar que a velhice dizia respeito ao outro, ou seja, era algo que não lhe pertencia: "Eu vejo que tô ficando velho, mas eu não gosto mais de me olhar no espelho. ... Eu não me sinto velho, mas tem gente que se sente né". Nesse sentido, Mucida (2017) traz que a velhice não é reconhecida pela própria pessoa de imediato, ela é algo do externo. Se a pessoa não reconhece o velho em si, o velho do espelho, pode se tornar uma outra pessoa, pois o velho é aquilo que não se quer ser.

Para M2, sua imagem lhe causava um sentimento tão hostil e de reprovação que ela retratou que seria capaz de quebrar o espelho. A participante parecia não encontrar mais a possibilidade de ser algo melhor ou de ver refletida uma imagem que agradasse o outro e a si mesma: "Eu tô mais enrugada, tô ficando velha, perdendo cabelo... que horror! Eu quebro o espelho” (M2). Dessa forma, se o eu não é mais seu próprio ideal, sentimentos negativos emergem das nuances de ser velho: as rugas, as olheiras, a pele flácida e os cabelos brancos (Baldin \& Vidal, 2017). Em contrapartida, H1 demonstrava ter uma boa relação com sua imagem no espelho, pois aceitava as marcas do envelhecer e elaborava as perdas sem sofrer um esvaziamento da libido.

Eu vou na frente do espelho, coloco um pouco de creme e digo... ah rosto véinho, tu tá te desbotando com o peso da idade, mas eu vou te cuida. . . E Eu noto que a gente com os anos, vai caindo e não adianta, é a natureza (H1).

Dessa forma, notou-se que a experiência de envelhecer trazia dificuldade para os participantes se reconhecerem e aceitarem a imagem refletida no espelho. O enfrentamento com a nova imagem poderia apontar o declínio físico e a impotência, assim como, poderia sinalizar um corpo se definhando devido à doença. Os registros do envelhecimento e do adoecimento seriam marcas de um corpo que já não é mais estereótipo de beleza, vitalidade e saúde. Não ver a própria imagem era uma forma de silenciar o diagnóstico já que a Aids acrescentaria ao corpo unificado uma mudança estética que denunciaria a doença, trazendo significantes da ordem do insuportável. 


\section{“- Tu tá com Aids! . . . - Eu perdi o chão”}

A Aids tem uma imensa força simbólica enquanto doença e causa ecos que envolvem questões da sexualidade humana (Bacchini et al., 2012; Pinheiro, 2013). Conforme Villela (2013), a notícia do HIV é uma experiência convulsionária que opera mudanças estruturais de grande porte. O corpo, agora atravessado por um vírus, recebe outra cartografia e demarca um novo modo de existência. A revelação do HIV atinge o sujeito e cristaliza a sua existência em uma nova categoria: a de ter que conviver com o vírus.

Constatou-se que para os entrevistados a descoberta do diagnóstico foi um momento marcado por surpresa e insegurança frente à doença, bem como por sentimentos de vergonha, tristeza, decepção e medo: "É uma mistura de sentimentos assim... de desespero, de insegurança, de vergonha, de medo... eu acho que é isso que a gente sente" (M1); "Báh, eu fiquei apavorado. Porque a gente vê na televisão e tudo... foi um descuido né, daí eu me apavorei" (H3).

Segundo Silva e Saldanha (2012), o medo, o desespero, a angústia e as alterações de humor são sentimentos comumente vivenciados pelas pessoas após receberem o diagnóstico da soropositividade do HIV. Nesse sentido, ao receber a notícia de uma doença, desencadeia-se um processo de luto no sujeito, visto que há uma perda concreta da saúde e da vitalidade (Veras, 2007; Villela, 2013). Jerusalinsky (1996) retrata, em sua abordagem psicanalítica do envelhecimento, a vivência de uma série de mudanças e perdas singulares ao processo da velhice que demandam ser elaboradas psiquicamente, como a perda do vigor físico e sexual. Esse processo instaura um desafio de se apropriar de um corpo que tem limitações, não desempenha mais a mesma performance e que é destituído de um lugar reconhecido de desejo.

Nos trechos de M2 e H2, percebe-se que havia a preocupação de o diagnóstico expor as experiências sexuais que ambos tiveram. Os participantes trataram o assunto como tabu por entenderem que o HIV não seria autorizado nessa fase da vida, de modo que se configura como a "doença do outro", já que ainda se propagam os mitos acerca de uma velhice assexuada: "Me deu um estado de nervo . . . Me dava vontade de chorar... depois de mulher véia, depois de mulher véia" (M2); "No início eu fiquei bem chateado, bem derrotado, sabe?! A gente acha que com a gente não vai acontecer" (H2).
No caso de M2, a revelação do diagnóstico teve repercussões em sua vivência sexual, pois suscitou um debate sobre questões de gênero e trouxe consequências psicossomáticas como forma de marcar no corpo o evento traumático. Segundo McDougall (1987/2000), a somatização serve como reação às dores mentais resultantes de um elevado nível de energia que não encontra representação e, portanto, não possibilita elaboração psíquica. Desse modo, algo precisa ser descarregado no corpo como uma atuação.

Observa-se pelo relato que M2 adquiriu o vírus de seu companheiro e, em suas reflexões, atribuía que a sexualidade do esposo e do homem é permitida independentemente da idade, enquanto para ela restava a castração. Nesse sentido, a participante não se autorizava mais a prática sexual e somatizava sintomas de dor na parte inferior de seus membros, por não permitir que a libido circulasse por essas partes de seu corpo. Essa reflexão revela a historicidade dos papéis e comportamentos de homens e mulheres, que envolvem as produções de sentido no cotidiano e as relações socioculturais de gênero.

Eu tenho muito frio da cintura pra baixo, minhas perna é um gelo, um gelo... Parece que isso aconteceu depois que eu peguei isso aí né.... Acredita que esses dias eu tinha uma sacola de camisinha e eu peguei e joguei tudo fora, eu não uso, pra quê? ... Não sinto mais vontade (M2).

Logo, compreende-se que o corpo erógeno se constrói apoiado no corpo biológico, como defendeu Freud (1905/1996) em Três Ensaios Sobre a Teoria da Sexualidade. Nesse sentido, é a partir do corpo pulsional que se encontra o corpo narcísico, que é investido de libido, e o corpo realidade, que investe libido no mundo externo; ambos totalizam a formação do ego. Assim, para a psicanálise o corpo é considerado principalmente corpo erógeno, fonte de desejo, prazer e dor.

Segundo Santos e Assis (2011), pelo fato de a sexualidade em idosos ser pouco investigada, permanece na sociedade e entre os profissionais de saúde a noção de que sexo e sexualidade não existem na velhice. Por isso, a clínica psicanalítica busca restabelecer o encontro desses sujeitos com seu desejo, pois o sujeito envelhecido precisa ser resgatado como um sujeito desejante. É preciso reconhecer, em primeiro lugar, que os sentimentos dos idosos não envelhecem, nem seus desejos (Brasil, Barcelos, 
Arrais, \& Cárdenas, 2013; Cherix, 2015; Corrêa, 2003; Messy, 1992). Contudo, estudos sobre o conhecimento de HIV/Aids na terceira idade enfatizam que os idosos não se veem vulneráveis à infecção e atribuem essa possibilidade aos jovens, aos usuários de drogas, aos homossexuais e aos profissionais do sexo (Bittencourt et al., 2015).

Em O estranho, Freud (1919/2010) explora a palavra alemã Unheimlich, que pode ao mesmo tempo assumir os significados de estranho e familiar. A partir disso, ele escreve sobre a angústia de desintegração do bebê, algo que um dia foi familiar, posteriormente recalcado, e que retorna como estranho despertando aflição e horror. As mudanças e inconstâncias do corpo atreladas ao processo de envelhecimento estão assim associadas à sensação do estranho, sendo o envelhecimento e a perda da funcionalidade do corpo sentidos como o retorno do recalcado. O corpo, algo familiar, com o processo de envelhecimento passa a ter outro registro e torna-se estranho e ameaçador (Cherix, 2015).

Desse modo, o HIV/Aids abala uma das maiores crenças narcísicas: a da imortalidade, na medida em que a morte pode ser vista como uma questão inquietante. A onipresença da morte causa a constante ameaça à integridade egóica do idoso que, ao passar pelo processo de envelhecimento, tem reativada essa angústia de aniquilamento (Goldfarb, 1998; Villela, 2013). Então, constrói-se uma interlocução entre o processo de envelhecimento e o sentimento de possuir o vírus do HIV/Aids, potencializando a sensação de algo inquietante, o estranho, que deveria ter ficado oculto e secreto, mas que se manifesta e revela a impotência e a fragilidade do sujeito (Bacchini et al., 2012; Villela, 2013). Notou-se que M1 e M3 apresentavam sentimentos de incredulidade e dúvida em relação à confirmação do HIV, tiveram dificuldade em elaborar a realidade traumática e foram resistentes quanto à aceitação da doença. As entrevistadas enfatizaram em seus discursos que, antes do diagnóstico, não tinham problemas de saúde e que havia muito tempo não mantinham relações sexuais.

Eu sei dos meus atos, eu sei que eu fui casada, eu tive um filho, eu me divorciei... Será que demora tantos anos pra aparecer essa doença? ... Eu não entendo isso aí, não me entra na cabeça, é isso que eu não me conformo (M3).
Em M1, as inquietações eram ainda mais latentes e a negação estava presente como uma forma de se proteger. Para ela, o HIV não estava em seu corpo e, assim, não reconhecia que possuía a doença. Ainda que não conseguisse eliminar o vírus, seguia tomando a medicação e realizava o tratamento, porém, questionava-se sobre como poderia ter HIV, buscando a todo custo justificativas que comprovassem sua crença de que poderia ter ocorrido um equívoco quanto a seu diagnóstico.

Eu te digo que eu não tenho HIV, porque se HIV pega no sexo, foi em 2013 a última vez que eu transei... Como que a doença não se desenvolveu? ... Botei na minha cabeça que eu não tenho, tomo medicação porque eu tive meningite, é isso! . . Eu ainda vou fazer um exame particular, porque erro humano existe (M1).

O vírus HIV aparece como um corpo estranho que o sujeito não reconhece como seu e não aceita, ainda que não possa eliminar. Com isso, apropriar-se desse corpo estranho, que é estigmatizado e um tabu social, torna-se um desafio de ordem psíquica, visto que não existem referências e recursos emocionais que amparem previamente essa vivência (Pinheiro, 2013; Villela, 2013). Como a Aids é uma doença que acomete o sujeito para além do corpo biológico, por questões ligadas à cultura, à moral ou à sexualidade, percebemos que são as relações afetivas que mais evidenciam a dimensão da dor (Bacchini et al., 2012; Serra et al., 2013).

Os pacientes relataram que a doença trouxe mudanças para suas vidas e para a relação que estabeleciam consigo mesmos e com os outros. Todos pareciam carregar uma dor, representada por uma ferida narcísica, que tinha como marca o sofrimento. $\mathrm{O}$ trecho de H3 ilustra que ao deparar-se com as perdas, que atualizaram a castração e trouxeram a constatação da própria finitude, os efeitos sofridos no corpo eram vivenciados no eu: "Vou levando como dá, mas o cara muda... muda alguma coisa na vida da gente, é difícil nê" (H3).

\section{"Isso aqui não vai sair das 4 paredes, eu não vou abrir pra ninguém"}

As características descritas no início da epidemia do HIV/Aids, que definiam a doença como contagiosa, incurável, mortal e ligada a homossexuais, vincularam-na aos estigmas e preconceitos advindos da posição social, da forma de contaminação e do comportamento sexual, estigmas que ainda 
continuam arraigados na sociedade (Garrafa, Godoi, \& Soares, 2012; Silveira, Batista, Colussi, \& Wibelinger 2011). A Aids, desde o começo, foi apresentada como uma doença que caminhava para um único destino: a morte. Além disso, em decorrência dessa "morte anunciada", o indivíduo com o vírus estava sujeito também à "morte civil” (Saldanha et al., 2009; Villela, 2013).

Os participantes mantinham o diagnóstico em segredo porque acreditavam que poderiam receber atitudes discriminatórias e sofrer preconceitos. Não era autorizado nem mesmo dentro da família comentar sobre a doença, de modo que o assunto permanecia em sigilo. Quando o diagnóstico era compartilhado, geralmente quem tinha conhecimento era apenas um dos filhos, tendo em vista que os participantes estavam acompanhados no momento da consulta de descoberta do HIV, como observado por M2, H1, H2 e H3: "Eu tava com o meu filho mais velho, mas ele sempre me apoiou. ... Só a única coisa que eu pedi, é que eu não queria que espalhasse. . . Só um filho sabe, o outro não sabe" (H2).

No caso de H3, apenas a filha sabia de seu diagnóstico e seus dois filhos mais velhos não tinham conhecimento; então, eles questionavam o motivo das consultas e exames frequentes que o pai realizava. Diante disso, H3, para não revelar a doença, dizia que ia para o hospital devido aos problemas de pulmão, já que era fumante. Percebe-se que o silêncio se fazia necessário como uma forma de proteger a si mesmo das represálias que poderiam surgir com o compartilhamento da doença; por isso, optava por deixar o assunto no campo do interdito: "A minha filha, desde que ela descobriu, ela que veio comigo, me apoiou, nunca me deixou sozinho. ... Os meus filhos não sabem... nem vamo falar... é entre eu e ela" (H3).

Já M1 e H4 haviam comentado sobre o diagnóstico com poucos amigos, enquanto M3 foi a única que nunca se autorizou a falar sobre esse assunto fora do ambiente médico. Quando recebeu o diagnóstico estava sozinha e decidiu que não compartilharia com mais ninguém a sua situação; então, apenas a equipe médica que a acompanhava sabia da doença. M3 enfatizou que, na entrevista, havia uma corresponsabilização por parte da entrevistadora em manter o sigilo das informações. Diante disso, evidenciou-se o medo e insegurança da participante em ter a condição de soropositiva.

No início foi terrível, eu aguentei sozinha... no osso do peito. . . É só eu e o médico! Eu não falei pro meu filho, eu não falei pra ninguém e eu não quero comentar com ninguém.... Essa é uma decisão que eu tomei. É meu. Vai ficar comigo e com os médicos, entendeu? E contigo que eu conversei agora (M3).

A Aids, além de ser uma doença com impacto na saúde física e psicológica, é acompanhada por estigmas socialmente construídos, que estão relacionados com as crenças sociais sobre a doença (Saldanha et al., 2009; Silva \& Saldanha, 2012). Segundo Serra et al. (2013), as representações dadas a Aids são: "doença do outro"; "incurável"; "fatal", que pode levar à morte e ao preconceito. Assim, a Aids na velhice é associada ao sofrimento causado pela incerteza da sobrevivência, pelo medo e pelo desprezo, já que se produz um discurso com conteúdo que causa constrangimento, sofrimento e restrições (Saldanha et al., 2009; Serra et al., 2013).

Nesse sentido, os participantes relataram que o sigilo era importante na medida em que lhes preservava de possíveis reações negativas dos outros. Eles também trouxeram que, dessa forma, não colocariam em risco suas representações identitárias, mantendo sua subjetividade enquanto sujeitos e evitando a representação social vinculada à doença. Sabe-se que o sexo continua sendo um tabu na contemporaneidade e, psiquicamente, o peso de carregar um estigma de promíscuo é devastador, pois leva à confrontação de aspectos inconscientes da sexualidade, como a castração e a proibição.

Observa-se isso nos trechos de M1 e H2: "Tu fica sem chão... Tu não pode conversar com qualquer pessoa, porque as pessoas hoje não sabem conversar, elas sabem acusar, sabe?" (M1; "As pessoas não têm essa liberdade ainda pra falar... a sociedade é muito discriminativa. Então se tu começar a falar alguma coisa, já começa aquele negócio de... não chega perto... parece que a pessoa é leproso" (H2).

Segundo Bacchini et al. (2012), o HIV/Aids parece reeditar os complexos infantis de castração incidindo não somente nas restrições do corpo, mas nas construções identitárias e nos ideais até então seguidos. Atrelados à condição de adoecimento, reflete-se que os desdobramentos do envelhecer também impõem um conjunto de renúncias narcísicas que se opõem aos desejos infantis de ser-tudo, ser-por-todo-o-tempo, ser investido sem obrigação de reciprocidade e dispor do objeto amado (Altman, 2011).

Nesse sentido, envelhecer sendo soropositivo para o HIV ou contrair o vírus na velhice representam um desafio duplicado para quem enfrenta essa situação. 
O impacto da doença nesse grupo etário não está apenas ligado ao diagnóstico, mas também ao fato de desvelar o tabu que envolve a ausência da sexualidade na velhice, por ser um hábito não aceito socialmente para tal fase da vida (Saldanha, Felix, \& Araújo, 2008; Silveira et al., 2011). Messy (1992) afirma que na circulação da libido não há jovem nem velho, o desejo não tem idade. Contudo, sabe-se que há um preconceito em reconhecer que na velhice há um sujeito desejante devido à dicotomia entre um psiquismo desejante e um corpo que não serve mais como meio de satisfação de desejo (Cherix, 2015).

Constatou-se que para as mulheres participantes a (con)vivência com o HIV trouxe limitações na construção de relacionamentos afetivos íntimos. Elas mesmas não se autorizavam mais a ocupar um lugar ativo em sua sexualidade, bem como expressaram que não tinham interesse em investir em relações afetivo-sexuais com homens. Acredita-se que essa postura era disparada pela condição de desamparo na qual o sofrimento, as incertezas, a solidão e até mesmo a ideia de não poder mais ser amadas pelo outro, são reativados com a ferida narcísica.

Eu acho que ninguém mais vai se despertar por mim, exatamente por isso... . Será que essa pessoa não vai me jogar na cara, não vai cansar de mim? Eu me questiono, então é uma coisa que eu risquei, não procuro, não quero, pra não me magoar (M1).

Pinheiro (2013) destaca que uma perda importante a ser elaborada na vivência de ser soropositivo tem relação com o narcisismo, pois a Aids resgata a condição humana de desamparo, por evocar o tema da morte e o medo da perda do amor do outro, sem o qual não se é sujeito. Diante disso, para M3 a ideia de revelar a doença para um suposto parceiro parecia insuportável, pois ela mesma tinha uma visão carregada de estigmas e preconceitos sobre a sexualidade e o HIV.

A participante M3 sentia-se interditada para a vida cotidiana e impedida de se relacionar integralmente com seu entorno. Da mesma maneira, a participante debateu sobre a questão das medidas protetivas, segundo as quais o preservativo pode ser entendido como uma forma de controle e repressão do prazer. Além disso, trouxe em seu relato as histórias amorosas de seu passado, admitindo que naquela época não havia a preocupação com medidas de proteção no sexo.
Nos anos 80 a gente não usava camisinha, a gente não tava nem aí, porque a gente namorava, transava, mas não se preocupava com a camisinha, sabe? . . . Hoje eu não tenho relação sexual com ninguém, porque isso é uma coisa minha e eu não quero dizer pra ninguém... mesmo porque eu não tenho direito, de que se por acaso, eu ficar com alguém, me interessar por alguém ou alguém se interessar por mim... eu não tenho o direito de transar sem o preservativo ... Dizer que eu tenho esse HIV eu não vou dizer pra ninguém (M3).

Segundo Carvalho (2003), o modelo patriarcal repreende a sexualidade da mulher, enquanto a sexualidade do homem pode ser exercida sem questionamentos e restrições. As mulheres parecem ficar presas à ideia de amor romântico que é marcado pelos ideais de completude em que uma pessoa completa a outra. Em nossa sociedade, é nítido que a discussão sobre sexualidade envolve preconceitos, preceitos religiosos e moralismo (Birman, 1980; Carvalho, 2003; Saldanha et al., 2008; Santos \& Assis, 2011).

Em contrapartida, os homens mantinham-se em atividade sexual e destinavam libido para o investimento de novas relações afetivo-sexuais. Percebeu-se que eles tinham um sentimento de culpa por terem se exposto ao risco de infecção e que caracterizavam a situação como um momento de descuido. Por isso, evitavam falar sobre a soropositividade, pois estariam expondo suas histórias de amor em que estava em jogo a busca pelo prazer. Outro elemento que compôs o discurso dos homens foi a autorrecriminação por terem depositado confiança em quem estavam se relacionando. $\mathrm{O}$ trecho de $\mathrm{H} 2$ representa essa análise:

O erro foi esse né... de não me preservar. . . Aí uma pessoa que eu comecei a conhecer começou a dizer... "Pra que preservativo? A gente tá tanto tempo junto, a gente se conhece." E eu fui naquela lábia... eu acho que foi ali que eu entrei... Nunca se pode confiar muito $(\mathrm{H} 2)$.

Falar de Aids é indispensável, pois essa doença fala das construções históricas e subjetivas da sexualidade, dos sexos, do desejo sexual e do corpo sexual (Birman, 1980). Nesse sentido, o ato de revelar ou não o diagnóstico para os mais próximos é atravessado por sofrimentos que trazem a complexidade de confiar aos outros essa situação. Conforme Garrafa 
et al. (2012), o medo do estigma e da discriminação desencoraja as pessoas que vivem com HIV a declararem sua sorologia. Assim, esconder a doença de quem pode aplicar-lhe o significado do estigma é uma atitude comum aos participantes.

Diante dessas considerações, ressalta-se a importância da promoção, por parte dos profissionais da saúde, de espaços de elaboração das vivências de ser idoso e ter o diagnóstico de HIV/Aids. Nesse contexto, os idosos soropositivos poderiam trocar experiências por meio do compartilhamento de angústias e conflitos que são semelhantes entre si, bem como desenvolver o sentimento de pertencimento a um grupo que lhes preste apoio e segurança.

\section{Considerações finais}

Os participantes deste estudo demonstraram dificuldade em reconhecer aimagem do espelho e navivência subjetiva do envelhecer e do adoecer. Entende-se que os idosos sofrem com as marcas do tempo e da doença, de uma maneira particular, e que essas marcas retratam as experiências de vida construídas.

Com a descoberta do diagnóstico, emergem sentimentos intensos que demonstravam o luto vivido pela perda de saúde e pela ameaça de castração. Dessa maneira, os entrevistados experienciavam a ideia recalcada de mortalidade com o susto da constatação da própria finitude. Assim, o diagnóstico não era compartilhado abertamente com os membros da família ou amigos; era algo velado entre os poucos que tinham conhecimento e entrava no campo do interdito.

Nesse sentido, a presente pesquisa buscou, por meio das informações levantadas, compreender os conflitos e vivências de envelhecer sendo soropositivo na sociedade atual, a fim de auxiliar no acolhimento e na escuta diferenciada dos idosos com HIV/Aids. No entanto, ainda há muito a se estudar a respeito dos significados e sentidos atribuídos a essa experiência que ressoa de modo singular na construção da identidade dos sujeitos. Portanto, diante das limitações metodológicas deste estudo, como o tempo de coleta, entende-se que este trabalho não tem o intuito de findar o conhecimento sobre o assunto, mas de contribuir para novas possibilidades de pesquisas, reflexões e produções de sentidos.

Desse modo, dialogar sobre a sexualidade no envelhecimento e criar programas de prevenção de HIV/ Aids específicos a essa faixa etária, são ferramentas úteis e necessárias para desmistificar tabus. Compreende-se que implementar políticas públicas cujos atores se responsabilizem por pensar o processo de envelhecimento associado a esse diagnóstico é um desafio, mas é o primeiro passo para que os idosos se autorizem a falar sobre suas vivências sexuais, como também elaborem questões pessoais que são fonte de sofrimento.

\section{Referências}

Altman, M. (2011). O envelhecimento à luz da psicanálise. Jornal de Psicanálise, 44(80), 193-206. http://pepsic.bvsalud.org/scielo.php?script=sci_arttext\&pid=S0103-58352011000100016\&lng=pt\&tlng=pt

Aragão, D. R. N., \& Chariglione, I. P. F. S. (2019). A percepção do tempo através do processo de envelhecimento. Psi UNISC, 3(1), 106-120. https://doi.org/10.17058/psiunisc.v3i1.12558

Bacchini, A. M., Alves, L. H. S., Ceccarelli, P. R., \& Moreira, A. C. G. (2012). Reflexões sobre o inquietante de ser portador de HIV/Aids. Tempo Psicanalítico, 44(2), 271-284. http://pepsic.bvsalud.org/scielo. php?script=sci_arttext\&pid=S0101-48382012000200002\&lng=pt\&tlng=pt

Baldin, T., \& Vidal, P. E. V. (2017). Sobre aquilo que se pode viver aos 80: Um estudo de caso acerca da velhice institucionalizada. Pesquisas e Práticas Psicossociais, 12(2), 344-360.http://pepsic.bvsalud.org/scielo. php?script=sci_arttext\&pid=S1809-89082017000200008\&lng=pt\&tlng=pt

Bardin, L. (2010). Análise de Conteúdo. Edições 70; LDA.

Birman J. (1980). Sexualidade na Instituição Asilar. Achiamé.

Bittencourt, G. K. G. D., Moreira, M. A. S. P., Meira, L. C. S., Nóbrega, M. M. L., Nogueira, J. A., \& Silva, A. O. (2015). Concepções de idosos sobre vulnerabilidade ao HIV/Aids para construção de diagnósticos de enfermagem. Revista Brasileira de Enfermagem, 68(4), 579-585. http:// doi.org/10.1590/0034-7167.2015680402i 
Brasil, K. T. R., Barcelos, M. A. R., Arrais, A. R., \& Cárdenas, C. J. (2013). A clínica do envelhecimento: Desafios e reflexões para a prática psicológica com idosos. Aletheia, (40), 120-133. http://pepsic.bvsalud.org/scielo. php?script=sci_arttext\&pid=S1413-03942013000100011\&lng=pt\&tlng=pt

Carvalho, J. A. (2003). O amor que rouba os sonhos: Um estudo sobre a exposição feminina ao HIV. Casa do Psicólogo.

Cherix, K. (2015). Corpo eenvelhecimento:Umaperspectivapsicanalítica. RevistaSociedade Brasileirade Psicologia Hospitalar, 18(1),39-51.http://pepsic.bvsalud.org/scielo.php?script=sci_arttext\&pid=S1516-08582015000100003\&lng=pt\&tlng=pt

Corrêa, C. P. (2003). Visão psicanalítica da idade numerada. Cogito, 5, 31-37. http://pepsic.bvsalud.org/scielo. php?script=sci_arttext\&pid=S1519-94792003000100005\&lng=pt\&tlng=pt

Elias, N. (2001). A solidão dos moribundos: Seguido de "envelhecer e morrer". Zahar.

Fontanella, B. J. B., Ricas, G., \& Turato, E. R. (2008). Amostragem por saturação em pesquisas qualitativas em saúde: Contribuições teóricas. Cadernos de Saúde Pública, 24(1), 17-27. https://doi.org/ 10.1590/S0102-311X2008000100003

Freud, S. (1996). Três ensaios sobre a teoria da sexualidade. In S. Freud, Edição standard brasileira das obras completas de Sigmund Freud (J. Salomão, Trad., Vol. 7, pp. 117-229). Imago. (Trabalho original publicado em 1905)

Freud, S. (2010). O Estranho. In S. Freud, Edição standard brasileira das obras completas de Sigmund Freud (J. Salomão, Trad., Vol. 17, pp. 233-270). Imago. (Trabalho original publicado em 1919)

Garrafa, V., Godoi, A. M. M., \& Soares, S. P. (2012). HIV/AIDS and the principle of non-discrimination and non-stigmatization. Revista Latinoamericana de Bioética, 12(2), 118-23.http://www.scielo.org.co/scielo. php?script=sci_arttext\&pid=S1657-47022012000200012\&lng=en\&tlng=en

Goldfarb, D. C. (1998). Corpo, tempo e envelhecimento. Casa do Psicólogo.

Jerusalinsky, A. (1996). Psicologia do envelhecimento. Correio da APPOA.

Lacan, J. (1998). O estádio do espelho como formador da função do eu. In J. Lacan, Escritos (V. Ribeiro, Trad., pp. 96-103). Zahar. (Trabalho original publicado em 1966)

McDougall, J. (2000). Teatros do corpo: O psicossoma em psicanálise. Martins Fontes. (Trabalho original publicado em 1987)

Messy, J. (1992). A pessoa idosa não existe. Aleph.

Minayo, M. C. S. (2011). Pesquisa social: Teoria, método e criatividade (31a ed.). Vozes.

Ministério da Saúde. (2017). Boletim Epidemiológico HIV/Aids. http://www.aids.gov.br/pt-br/pub/2017/ boletim-epidemiologico-hivaids-2017

Mucida, A. (2017). O sujeito não envelhece..Psicanálise e velhice. Autêntica.

Neri, A. L. (1991). Envelhecer num país de jovens: Significados de velho e velhice segundo brasileiros não idosos. Editora da Unicamp.

Organização das Nações Unidas. (2003). Plano de ação internacional para o envelhecimento. Ministério da Justiça. http://www.observatorionacionaldoidoso.fiocruz.br/biblioteca/_manual/5.pdf

Pinheiro, A. C. S. (2013). A pesquisa em psicanálise no hospital: Corpos marcados pelo HIV/Aids. [Dissertação de Mestrado, Universidade Federal do Pará ]. Programa de Pós-Graduação em Psicologia. http://ppgp.propesp.ufpa.br/index.php/br/teses-e-dissertacoes/dissertacoes/196-1turma-2011

Resolução $n^{o} 510$ (2016, 7 de abril). https://www.in.gov.br/materia/-/asset_publisher/Kujrw0TZC2Mb/content/ $\mathrm{id} / 22917581$

Rosa, C. M., Veras, L., \& Assunção, A. (2015). Reflexos do tempo: uma reflexão sobre o envelhecimento nos dias de hoje. Estudos e Pesquisas em Psicologia, 15(3), 1027-1044.http://pepsic.bvsalud.org/scielo. php?script=sci_arttext\&pid=S1808-42812015000300014\&lng=pt\&tlng=pt

Rosa, C. M., \& Vilhena, J. (2015). Envelhecimento e seus possíveis destinos: Uma reflexão acerca do trabalho do negativo. Revista Tempo Psicanalítico, 47(1), 112-133. http://pepsic.bvsalud.org/scielo. php?script=sci_arttext\&pid=S0101-48382015000100009\&lng=pt\&tlng=pt 
Rosa, C. M., \&Vilhena, J. (2016). O silenciamento da velhice: Apagamento social e processos de subjetivação. Revista Subjetividades, 16(2), 9-19. https://doi.org/10.5020/23590777.16.2.9-19

Roudinesco, E., \& Plon, M. (1998). Dicionário de psicanálise. Zahar.

Saldanha, A. A. W., Felix, S. M. F., \& Araújo, L. F. (2008). Representações sobre a Aids na velhice por coordenadoras de grupos da terceira idade. Revista Psico-USF, 13(1), 95-103. https://doi.org/10.1590/S1413-82712008000100012

Saldanha, A. A. W., Araújo, L. F., \& Sousa, V. C. (2009). Envelhecer com Aids: Representações, crenças e atitudes de idosos soropositivos para o HIV. Revista Interamericana de Psicologia, 43(2), 323-332.http://pepsic.bvsalud.org/ scielo.php?script=sci_arttext\&pid=S0034-96902009000200013\&lng=pt\&tlng=pt

Santos, A. F. M., \& Assis, M. (2011). Vulnerabilidade das idosas ao HIV/AIDS: Despertar das políticas públicas e profissionais de saúde no contexto da atenção integral: Revisão de literatura. Revista Brasileira de Geriatria e Gerontologia, 14(1), 147-157. https://doi.org/10.1590/S1809-98232011000100015

Serra, A., Sardinha, A. H. L., Pereira, A. N. S., \& Lima, S. C. V. S. (2013). Percepção de vida dos idosos portadores do HIV/AIDS atendidos em centro de referência estadual. Saúde em Debate, 37(97), 294-304.http://www.scielo.br/ scielo.php?script=sci_arttext\&pid=S0103-11042013000200011\&lng=en\&tlng=pt

Silva, B. R., \&Finocchio, A.L. (2011).Avelhicecomo marca da atualidade:Uma visão psicanalítica. RevistaVínculo, 8(2), 23-30.http://pepsic.bvsalud.org/scielo.php?script=sci_arttext\&pid=S1806-24902011000200004\&lng=pt\&tlng=pt

Silva, J., \& Saldanha, A. A. (2012). Vulnerabilidade e Convivência com o HIV/AIDS em pessoas acima de 50 Anos. Revista Mal-estar e Subjetividade, 12(3-4), 817-852.http://pepsic.bvsalud.org/scielo. php?script=sci_arttext\&pid=S1518-61482012000200014\&lng=pt\&tlng=pt

Silveira, M. M., Batista, J. S., Colussi, E. L, \& Wibelinger, L. M. (2011). Sexualidade e envelhecimento: Discussões sobre a AIDS. Revista Temática Kairós Gerontologia, (5)14, 205-220. https://doi.org/10.23925/2176-901X.2011v14iEspecial10p205-220

Triviños, A. N. S. (1987). Introdução à pesquisa em ciências sociais: A pesquisa qualitativa em educação. Atlas.

Turato, E. R (2013). Tratado da metodologia da pesquisa clínico-qualitativa: Construção teórico-epistemológica discussão comparada e aplicação nas áreas da saúde e humanas (6a ed.). Vozes.

Veras, J. F. (2007). Adoecimento psíquico em mulheres portadoras do vírus HIV: Um desafio para a clínica contemporânea. Psicologia: Ciência e Profissão, 27(2), 266-275. https://doi.org/10.1590/S1414-98932007000200008

Villela, A. B. (2013). A atualidade da psicanálise: Do HIV à escuta pulsional. Cadernos de Psicanálise, 35(29), 77-87. http://pepsic.bvsalud.org/scielo.php?script=sci_arttext\&pid=S1413-62952013000200005\&lng=pt\&tlng=pt

Vilhena, J., Novaes, J. V., \& Rosa, C. M. (2014). A sombra de um corpo que se anuncia: Corpo, imagem e envelhecimento. Revista Latinoamericana Psicopatologia Fundamental, 17(2), 251-264. https://doi.org/10.1590/1984-0381v17n2a08

\section{Isadora Cristina Putti Paludo}

Psicóloga. Especialista em Saúde com Ênfase em Alta Complexidade pelo Programa de Residência Integrada Multiprofissional da Universidade Federal de Santa Catarina (UFSC). Mestranda em Psicologia pelo Programa de Pós-graduação em Psicologia da Universidade Federal de Santa Catarina (UFSC), Florianópolis - SC. Brasil.

E-mail: isaapaludo@gmail.com

(1) https://orcid.org/0000-0002-7908-4424

\section{Luisa da Rosa Olesiak}

Psicóloga. Doutoranda em Psicologia pelo Programa de Pós-graduação em Psicologia da Universidade Federal de Santa Maria (UFSM), Santa Maria - RS. Brasil. Membro do Núcleo de Estudos Interdisciplinares em Saúde da UFSM.

E-mail: luisa.drolesiak@gmail.com

(1) https://orcid.org/0000-0002-2635-2675 


\section{Alberto Manuel Quintana}

Psicólogo. Doutor pela Pontifícia Universidade Católica de São Paulo (PUC-SP). Docente no Curso de Graduação e no Programa de Pós-Graduação de Psicologia da Universidade Federal de Santa Maria (UFSM), Santa Maria - RS. Brasil.

E-mail: albertom.quintana@gmail.com

(1) http://orcid.org/0000-0001-7356-6142

Endereço para envio de correspondência:

Universidade Federal de Santa Maria. Av. Roraima, 1000, Cidade Universitária, Prédio 74B, Sala 3212A, Camobi. CEP: 97105-970. Santa Maria - RS. Brasil.

Recebido 16/05/2019

Aceito 05/10/2020

Received 05/16/2019

Approved 10/05/2020

Recibido 16/05/2019

Aceptado 05/10/2020

Como citar: Paludo, I. C. P., Olesiak, L. R., \& Quintana, A. M. (2021). Idosos soropositivos: A construção de significados para o envelhecimento com HIV/Aids. Psicologia: Ciência e Profissão, 41, 1-15.

https://doi.org/10.1590/1982-3703003224079

How to cite: Paludo, I. C. P., Olesiak, L. R., \& Quintana, A. M. (2021). Aged HIV seropositives: The construction of meanings for aging with HIV/AIDS. Psicologia: Ciência e Profissão, 41, 1-15. https://doi.org/10.1590/19823703003224079

Cómo citar: Paludo, I. C. P., Olesiak, L. R., \& Quintana, A. M. (2021). Ancianos seropositivos: La construcción de significados para el envejecimiento com VIH/SIDA. Psicologia: Ciência e Profissão, 41, 1-15.

https://doi.org/10.1590/1982-3703003224079 